\title{
NUEVA CONSTITUCIÓN Y REFORMA CONSTITUCIONAL: \\ EL CONTENIDO DE LA FORMA
}

\author{
Fernando Atria Lemaitre
}




\section{FERNANDO ATRIA LEMAITRE}

Doctor de la Universidad de Edimburgo y abogado de la Universidad de Chile. Es Profesor Asociado de la Facultad de Derecho de esa misma Casa de Estudios. Es autor de "On Law and Legal Reasoning" (Oxford, 2002), "Mercado y ciudadanía en la educación” (Santiago, 2007), "La mala educación: ideas que inspiran al movimiento estudiantil en Chile" (Santiago, 2012), "Veinte años después: neoliberalismo con rostro humano" (Santiago, 2013), "La constitución tramposa” (Santiago, 2013), "Derechos sociales y educación: un nuevo paradigma de lo público" (Santiago, 2014) y, más recientemente, "La forma del derecho" (Madrid, 2016). También es coautor del libro "El otro modelo: del orden neoliberal al régimen de lo público" (Santiago, 2013). 


\section{NUEVA CONSTITUCIÓN Y REFORMA CONSTITUCIONAL: EL CONTENIDO DE LA FORMA}

\section{INTRODUCCIÓN}

Se habla de nueva Constitución en Chile. Pero no se habla en un lenguaje común, por lo que lo que parece discusión es en buena medida un diálogo de sordos, un intercambio de palabras a las que cada participante le atribuye un significado distinto. Esto hace que los desacuerdos de verdad no alcancen a aparecer, escondidos detrás de cuestiones verbales. Si las desavenencias verdaderas aparecieran, lo que uno esperaría encontrar es diversas personas o grupos asumiendo posiciones encontradas respecto de algo. Así, unos dirían "sí" a la nueva Constitución o a la asamblea constituyente y otros dirían "no". Pero la discusión constitucional no aparece así: en vez, vemos a unos defendiendo la necesidad de una nueva Constitución y a otros diciendo que la posición de los primeros no es errada, sino absurda, un sinsentido, porque lo que importa no es si una Constitución es nueva o no, sino cuál es su contenido.

Lo que esto muestra es que no podemos asumir que los conceptos que utilizamos son conceptos compartidos y que la controversia radica en asumir una posición de "sí" o "no" respecto de ellos (la nueva Constitución, la asamblea constituyente, etc.). Uno esperaría que los que se dedican académicamente al estudio del derecho constitucional habrían sido capaces, a estas alturas, de elaborar un aparataje conceptual que sirviera para clarificar los puntos y aclarar las cuestiones, de modo que los ciudadanos tuviéramos un lenguaje común a través del cual expresar nuestros desacuerdos. Pero no lo han hecho, probablemente porque han estado, desde 2005, demasiado ocupados en alegar causas ante el Tribunal Constitucional. La consecuencia es la indicada más arriba: cuando discutimos sobre la nueva Constitución no alcanzamos a llegar a las cuestiones que son realmente importantes en la discusión y nos quedamos entrampados en disputas verbales sobre si la Constitución actual es "la misma" que en 1980, etc. Como veremos, el problema es que las reflexiones constitucionales de los especialistas en el tema no se toman en serio el problema constituyente, porque incluso cuando son conscientes (como explicaremos) de que las cuestiones constitucionales son cuestiones políticas, no entienden el modo en que los conceptos que utilizan son conceptos cuyo contenido viene dado por la política. 
Por consiguiente, en el resto de este artículo me gustaría mostrar por qué necesitamos de un lenguaje algo más sofisticado teóricamente del que hoy tenemos, y cuáles son las características de ese lenguaje. Luego pretendo explicar, para entender nuestra situación político-constitucional actual, los conceptos de constitución, reforma constitucional y poder constituyente.

Por cierto, no puedo pretender que yo hablo desde una torre de marfil. He defendido en varios trabajos anteriores una determinada posición respecto de la causa del problema constitucional, sus características y las formas genéricas de su solución ${ }^{1}$. Pero aunque no puedo pretender neutralidad, sí puedo al menos decir que las explicaciones que siguen a continuación pretenden ser clarificaciones conceptuales. En otras palabras, en lo que sigue no pretendo abogar por una determinada solución, sino explicar los términos en los que a mi juicio el problema puede ser fructíferamente discutido ${ }^{2}$.

\section{LA DISTINCIÓN ENTRE NUEVA CONSTITUCIÓN Y REFORMA CONSTITUCIONAL}

Una de las ideas que se escucha hoy más insistentemente es que la discusión constitucional ha estado por demasiado tiempo dedicada a la forma, en condiciones de que lo que realmente importa es la sustancia; que debemos dejar de hablar del mecanismo y comenzar a hablar del contenido. Que si supiéramos cuál es el contenido que queremos, entonces quizás nos daríamos cuenta de que puede lograrse mediante una reforma constitucional, por lo que todas las apelaciones a la asamblea constituyente serían innecesarias, etc.

Lo que sugieren quienes sostienen esta posición es que en principio podemos distinguir el proceso constituyente de la nueva Constitución. O mejor dicho, el proceso (sea cual fuere) del resultado (sea cual fuere). Éste es quizás un buen punto para comenzar nuestra discusión: ¿es correcto entender que en la cuestión constitucional el proceso y el producto son independientes en el sentido de que en principio cualquier producto puede manifestarse a través de cualquier proceso y viceversa?

1. Atria: La Constitución Tramposa (Santiago: Lom, 2013) y posteriormente Atria: "Sobre el problema constitucional y el mecanismo idóneo y pertinente", en Fuentes y Joignant (eds): La Solución Constitucional (Santiago: Catalonia, 2015), pp. 41-70, Atria: "La constitución tramposa y la responsabilidad del jurista", en Zúñiga (ed): Nueva Constitución y Momento Constitucional (Santiago: Legal Publishing, 2014).

2. Atria: "Sobre el problema constitucional y el mecanismo idóneo y pertinente". 
Lo que intentaré explicar es que cuando las cosas se miran con cuidado y no sólo superficialmente, es claro que esto no es así. Que, tratándose del cambio constitucional, el tipo de producto buscado se anticipa en el proceso, de modo que hablar acerca del proceso es una manera de hablar acerca del producto. En este sentido, podemos entender mejor cuál es el proceso adecuado cuando tenemos claridad respecto de su producto. La conclusión será, por eso, que hoy la manera más políticamente autoconsciente de hablar del contenido es hablar del mecanismo.

Pero es claro que esta idea va contra el sentido común, que nos muestra que en muchos contextos cotidianos proceso y producto son dos cosas que pueden ser distinguidas. Al decir que eso no es así en lo que se refiere al proceso constituyente y la nueva Constitución, no pretendo invocar misticismos de los que se usan de forma habitual cuando se habla del momento constituyente. Pretendo mostrar por qué, en un sentido políticamente evidente, el producto se anticipa en el proceso. La clave para entender el lenguaje constitucional está en restablecer su vinculación con el lenguaje de la política, porque después de todo, el derecho constitucional no es sino política institucionalizada. Al interpretar políticamente los conceptos constitucionales, ganaremos en entendimiento.

El producto buscado es una nueva Constitución, no una reforma constitucional. Pero la distinción entre estas dos cuestiones es mucho menos obvia de lo que podría parecer a primera vista ${ }^{3}$. Esto puede apreciarse mirando la discusión que siguió a la publicación de la ley 20.050, que hoy conocemos como la reforma constitucional de 2005. Vista desde hoy, esa discusión se nos aparece curiosamente invertida. Esto es lo que hace a este episodio crucial ahora que hablamos de nueva Constitución. Nos provee, por así decirlo, de una imagen en negativo del poder constituyente, un momento en que todos entendieron las cosas al revés. El Presidente Lagos y la Concertación entendieron que el problema constitucional había sido solucionado porque la Constitución ya no era la de 1980 o “de Pinochet” y podía ser lícitamente llamada “de 2005”. El propio Lagos, al promulgar la ley 20.050, afirmó que después de esas reformas "Chile cuenta $[. .$.$] con una Constitución que ya no nos divide,$ sino que es un piso institucional compartido". La derecha se opuso a esta nueva denominación. El diario El Mercurio sostenía que las reformas "no alteran en lo sustancial el texto de 1980", mientras que el entonces senador Andrés Chadwick sostuvo algo que hoy sería considerado como un argumento para respaldar la demanda por una nueva Constitución:

3. Este párrafo y el siguiente incorporan material de Atria: La Constitución Tramposa, pp. 16-17. 
por muy importante que hayan sido las reformas, que hemos compartido y consensuado, sigue siendo la Constitución de 1980. Se mantienen sus instituciones fundamentales, tal como salió de su matriz. Para que haya una nueva constitución se requiere de un proceso constituyente originario, no de un proceso de reformas ${ }^{4}$.

La interrogante, entonces, por la diferencia entre una reforma constitucional y una nueva Constitución, una cuestión que pareciera corresponder a los cursos de teoría de la Constitución, es una pregunta políticamente relevante hoy. Y, adicionalmente, ya tenemos una pista: no podemos descansar en lo que los agentes creen que están haciendo, porque éstos pueden estar tan equivocados como el comentarista o el jurista. Y como de lo que se trata es de entender la demanda por una nueva Constitución, es importante hoy reflexionar para tener un criterio que podamos utilizar cuando llegue el momento. Esto es, un criterio que nos permita saber si lo que realmente necesitamos es una nueva Constitución o es suficiente una reforma constitucional que nos permita tanto entender por qué la diferencia entre estas dos cuestiones es importante como diferenciar una de otra para no repetir el error de Lagos en 2005.

Una manera de responder a la pregunta por la diferencia entre una nueva Constitución y una reforma constitucional es hacerlo con uno de los juristas más reconocidos del siglo XX, Hans Kelsen. En su explicación, lo que define a una nueva Constitución es que es dictada a través de mecanismos no previstos en la Constitución anterior. Una reforma constitucional, por su parte, es cualquier modificación del texto constitucional obtenida mediante el ejercicio de potestades constitucionales ordinarias de reforma (en el caso chileno, las hoy contenidas en el capítulo XV del texto constitucional):

Las constituciones escritas contienen por lo común determinaciones especiales relativas a los procedimientos mediante los cuales solamente ellas pueden ser modificadas. El principio de que la norma de un orden jurídico vale durante todo el tiempo que transcurra hasta que su validez no sea terminada en la manera determinada por ese orden jurídico, o hasta que sea remplazada por la validez de otra norma de ese orden jurídico, es el principio de legitimidad.

4. La opinión editorial de El Mercurio fue publicada el 23 de septiembre de 2005. La opinión de Chadwick está consignada en "Denominación de la Constitución abre debate entre juristas y parlamentarios”, El Mercurio, 21 de septiembre de 2005. 
Este principio, con todo, se aplica a un orden jurídico estatal con una limitación altamente significativa. No tiene aplicación en caso de revolución. Una revolución, en el sentido amplio de la palabra, que abarca también el golpe de Estado, es toda modificación no legítima de la Constitución —es decir, no efectuada conforme a las disposiciones constitucionales- o su remplazo por otra. Visto desde un punto de vista jurídico, es indiferente que esa modificación de la situación jurídica se cumpla mediante un acto de fuerza dirigido contra el gobierno legítimo, o efectuado por miembros del mismo gobierno; que se trate de un movimiento de masas populares, o sea cumplido por un pequeño grupo de individuos. Lo decisivo es que la Constitución válida sea modificada, o remplazada enteramente, por una nueva Constitución, de una manera que no se encuentra prescripta en la Constitución hasta entonces válida ${ }^{5}$.

Nótese que, como lo deja en claro la frase destacada, para Kelsen lo importante no es la continuidad del texto. La distinción no es entre el caso en que el texto es modificado y el caso en que es reemplazado enteramente. Si cualquiera de esas cosas se hace mediante el ejercicio de potestades constituidas, es una reforma constitucional, una modificación de la Constitución vigente. Si se hace a través de formas distintas, es una nueva Constitución. La respuesta kelseniana (jurídica) es puramente formal, no mira en absoluto al contenido.

Está claro que, por eso mismo, es una respuesta que políticamente nos deja donde mismo estábamos. Lo que nosotros necesitamos es entender la diferencia entre reforma constitucional y nueva Constitución, para entonces poder determinar si lo que necesitamos es una nueva Constitución y, en ese caso, si ella puede darse o no a través de mecanismos ordinarios de reforma. Una explicación teórica como la de Kelsen va en dirección contraria, por así decirlo: si se sigue la forma institucional es una reforma, si no se sigue es una nueva Constitución. Pero eso no nos ayuda a determinar si lo que Chile necesita es algo que puede obtenerse mediante el ejercicio de poderes normales de reforma o no.

¿Será que la cuestión es menos relevante de lo que parece? Al presentar la lista de las 80 modificaciones sugeridas al debate constituyente por Chile Vamos, al senador Alberto Espina le preguntaron si la aprobación de esas reformas implicaría una nueva Constitución o sólo una reforma constitucional. El senador respondió:

5. Kelsen: Teoría Pura del Derecho (1960) (México: Porrúa, 1991; ed.orig. 1960), pp. 119-120 (énfasis añadido). 
Ese es un tema que no tiene mucha significación, porque cuando se presente un proyecto de reforma constitucional lo que se va a aprobar va a ser probablemente gran parte de las cosas que tiene la actual Constitución, que son muy buenas, y se van a cambiar aquellas que se puedan perfeccionar. Ese es un debate ideológico, la izquierda quiere eliminar la Constitución de 1980 porque dice que es la Constitución de Pinochet, lo que es falso. Porque el propio Presidente Lagos señaló que esta Constitución era democrática, que había eliminado todos los enclaves autoritarios y la firma él ${ }^{6}$.

La idea aquí es que el producto buscado puede ser llamado "nueva Constitución" o "reforma constitucional", pero que eso es una cuestión de palabras. Lo que importa es cuáles son las reformas que se aprueben y qué juicio merece el texto final. Uno podría darle una forma kelseniana a la explicación del senador Espina: si lo único que diferencia a la reforma constitucional de la nueva Constitución es el procedimiento institucional o no de su adopción, entonces no nos enredemos en eso. Primero discutamos sobre los contenidos, sobre lo que queremos, y luego veamos si ese contenido que nos interesa puede asumir forma constitucional a través de los procedimientos de reforma. En ese caso, se reforma la Constitución. Kelsen dirá que se trata de una "reforma", no de una nueva Constitución, en tanto se ha dictado a través de los poderes constituidos; pero a nosotros, los ciudadanos, no nos importa mucho lo que digan los teóricos. Que ellos usen el lenguaje como les parezca adecuado. Nosotros no nos perdemos y nos es indiferente cómo llamamos a las cosas; lo que nos importa es cómo las cosas son.

A mi juicio, esta manera de explicar nuestra situación constitucional es totalmente equivocada. Es decir, es una vía de aproximarse al problema que no alcanza a entender los términos que ocupa, que no entiende su dimensión política, que no nota lo que importa y se queda sólo en lo superficial. Es esto lo que en buena parte explica el hecho de que el problema sea tan incomprendido, que sea tan recurrente esto de decir (como Lagos el 2005) que el problema está solucionado sólo para descubrir, un (poco) tiempo después, que sigue ahí. No podemos pretender avanzar sin entender la situación en la que estamos.

\section{DOS CONCEPTOS DE “CONSTITUCIÓN”}

Uno de los conceptos que no podemos dar por sentado es el de Constitución: no podemos asumir que tenemos claro qué es, de modo que nuestro desacuerdo

6. En El Diario Financiero, 24 de marzo de 2016. 
gire sólo en torno a si necesitamos reformar la que tenemos o dictar una nueva. Debemos comenzar preguntándonos qué es una Constitución. Sólo por referencia al concepto de constitución podremos entender los conceptos relacionados de poder constituyente (y poder constituido), nueva Constitución y reforma constitucional, etc.

\section{La respuesta del abogado: es un texto}

Hay dos maneras de entender el concepto de "constitución". Una es la manera del abogado, para quien lo más importante acerca de la Constitución es que ella le provee reglas que permiten alegar causas ante tribunales. Para el abogado, ésta es un conjunto de reglas, reglas que en cuanto a su tipo no son diversas de otras reglas jurídicas, como las legales. ¿Qué es lo que distingue, entonces a una Constitución? El abogado responde: la forma en que se modifica. A diferencia de las reglas legales, las reglas constitucionales son especialmente difíciles de modificar. Esto ha sido elevado a la categoría de nota conceptualmente definitoria de "constitución" por algunos juristas:

Las constituciones [...] son rígidas por definición, en el sentido de que una Constitución no rígida no es en realidad una Constitución, sino una ley ordinaria ${ }^{7}$.

La Constitución, entonces, es un libro de reglas escritas, un texto (los abogados suelen hablar, de hecho, de "el texto constitucional"). Este texto se caracteriza por ser especialmente difícil de modificar. En el caso del texto constitucional chileno, sus condiciones de modificación están fijadas en el artículo 127, que exige la concurrencia del voto de $2 / 3$ o $3 / 5$ de los senadores y diputados en ejercicio.

Varias cuestiones importantes se siguen de entender "constitución" de este modo. Si es un texto, una nueva Constitución será un nuevo texto. ¿Cómo distinguir un texto modificado de un texto nuevo? En estricto rigor, cualquier modificación de un texto hace que el texto sea diferente, y si el texto es diferente será un nuevo texto, y si es un nuevo texto será una nueva Constitución. Pero esto sería una observación más bien pedante, y como no nos permite distinguir reforma constitucional de nueva Constitución (porque lleva a la conclusión de que cualquier reforma, por pequeña que sea, sería una nueva Constitución), no nos sirve. Por otro lado, igualmente

7. Ferrajoli: "Democracia constitucional y derechos fundamentales. La rigidez de la constitución y sus garantías", en Ferrajoli, Moreso y Atienza, La Teoría del derecho en el Paradigma Constitucional (Madrid: Fundación Coloquio Jurídico Europeo, 2008) aquí p. 92. 
pedante e inútil sería sostener que una nueva Constitución es un texto enteramente nuevo. Por consiguiente, si la Constitución es un texto, parece claro que la única respuesta razonable a la pregunta de cuándo se trata de una nueva Constitución es: cuando el nuevo texto sea suficientemente distinto del texto antiguo.

Ahora bien, ¿cuán diferente es "suficientemente" diferente? La respuesta es en buena medida una cuestión de apreciación. Es decir, es razonable pensar que para dos observadores la misma diferencia será en un caso "suficientemente" considerable y en el otro, no. Y no hay siquiera un principio de criterio independiente para determinar quién podría estar equivocado y quién no en esta diferencia. Esto no quiere decir que no tenga sentido hablar de nuevos textos y de textos reformados. Pero sí quiere decir que nada demasiado importante puede depender de una diferencia que reside tan evidentemente en los ojos del observador. Por consiguiente, si la Constitución es un texto, entonces el senador Espina tiene razón: nada importante se juega en las palabras que ocupemos; si al nuevo texto lo describimos diciendo que es un texto nuevo o lo describimos diciendo que es el texto antiguo reformado. Mejor discutamos derechamente el contenido de ese texto.

De hecho, esta idea de que la Constitución es un texto nos permite entender lo que dicen quienes insisten una y otra vez en que la Constitución bajo la cual vivimos ya no es la "de Pinochet", porque ha sido tan modificada. Es verdad que el texto constitucional ha sido modificado como pocos otros textos legales del derecho chileno. En efecto, si no es el texto legal que más modificaciones ha tenido en la historia del derecho chileno, debe estar muy arriba en la lista. Dicho de otro modo, si un texto es "nuevo" cuando es suficientemente distinto del texto anterior, hay buenas razones para afirmar que, respecto del texto de 1980, el texto actualmente vigente es "nuevo". Podrá haber desacuerdo o diferencias de opinión en cuanto al momento preciso en que esto ocurrió (¿1989, 2005?), pero al menos desde mi punto de vista, el texto actualmente vigente es "suficientemente" distinto al texto de 1980 como para que sea razonable decir que son dos textos diferentes.

Todo esto, por cierto, no quiere decir que la diferencia entre reforma constitucional y nueva Constitución sea una cuestión de palabras, ni que la actual ya no sea la "de Pinochet", etc. Todas estas conclusiones se siguen de la tesis de que la Constitución es un texto difícil de reformar. Pero esta tesis es evidentemente insuficiente, ya que no nos permite una comprensión más profunda de la situación en la que nos encontramos. Es decir, hace irrelevantes cuestiones que son importantes, e importantes cuestiones que son irrelevantes. A mi juicio, en esta manera superficial de entender el concepto de Constitución está la explicación de que la discusión constitucional parezca tanto un diálogo de sordos. Independientemente de la posición que en definitiva cada uno adopte respecto de la cuestión de la nueva Constitución, nos ayudaría a todos manejar conceptos más sofisticados al respecto. 


\section{La respuesta política: es una decisión fundamental sobre el poder}

Ese concepto más complejo tiene que abandonar la idea de que una Constitución es un texto y comenzar preguntándose por el sentido político que tiene. El punto de partida ha de ser: ¿por qué importa una Constitución?

La respuesta que deberíamos considerar es: porque es una decisión fundamental, una decisión que constituye, por eso se llama "constitución". ¿Constituye qué? Es simple: constituye el poder político.

Nótese que nosotros entendemos que un sistema democrático necesita descansar en una Constitución. Eso, que nos puede parecer obvio y natural, no tiene nada de obvio ni de natural. El solo hecho de que entendamos que un sistema democrático supone una Constitución tiene consecuencias importantes acerca de nuestro modo de entender el Estado y lo político. Implica, por ejemplo, que creemos que el Estado civil y el poder político no son naturales, no fluyen inmediatamente del hecho de que los seres humanos habitan el mundo. El poder político es artificial, necesita ser políticamente constituido ${ }^{8}$. Y, de nuevo, ya de esto se siguen consecuencias políticamente relevantes: si el poder político no es natural, si es artificial, su existencia plantea un problema de legitimación que los órdenes naturales no plantean. La respuesta a este dilema de legitimación planteado por la artificialidad del poder político (la idea fundamental afirmada por el concepto de constitución) es el poder constituyente del pueblo. Pero no nos apresuremos.

Ahora volvamos al inicio, a la idea de que la Constitución no es un texto, sino una decisión fundamental sobre la forma del poder. Si esto es así, tendremos que decir que mientras esa decisión no cambie, la Constitución será la misma. Esto nos da un criterio para distinguir reforma constitucional de nueva Constitución: una modificación de las decisiones fundamentales sobre la forma del poder implicará una nueva Constitución, mientras que una modificación del texto constitucional (en el sentido anterior del abogado) que no implique una transformación de la decisión fundamental será una reforma constitucional.

Porque una consecuencia obvia de este concepto ("político") es que no todo lo que el abogado llama "constitución" es Constitución. Recuérdese que para el abogado la Constitución es un texto, caracterizado por su especial dificultad de reforma. Pero si no es un texto, sino una o varias decisiones fundamentales sobre la forma del poder, entonces es obvio que en principio es posible, (a) que partes de esa decisión no estén en el texto difícil de modificar que el abogado llama "Constitución", y (b) que parte de ese texto no sea constitucional.

8. Arendt: On Revolution (Harmondsworth: Penguin, 1977; ed.orig. 1963), p. 19. 
Ahora bien, ¿cómo diferenciar en el texto constitucional (o incluso fuera de él) lo que es la Constitución de lo que es sólo parte de él?

\section{Constitución y leyes constitucionales}

Lo primero que debemos hacer para hablar de las cosas es ponerles nombre. La distinción por la que ahora nos estamos preguntando es la distinción entre Constitución y leyes constitucionales. La Constitución es la o las decisiones fundamentales sobre la forma del poder, al tiempo que las leyes constitucionales son decisiones que, como las leyes en general, presuponen una decisión fundamental (una Constitución). Es decir, pertenecen al género de las leyes, y su diferencia específica es que están sujetas a las condiciones de reforma y las dificultades del texto constitucional. Ante esto, el abogado se confunde y entiende que son parte de la Constitución, que cuando ellas cambian, "cambia" la Constitución. Pero si uno entiende "constitución" como la decisión fundamental sobre la forma del poder, es obvio que muchas de las partes del texto constitucional no son Constitución.

¿Cómo distinguirlas? ¿Cómo separar, en el texto constitucional, la Constitución de las leyes constitucionales? ¿Cómo diferenciar un cambio en las leyes constitucionales (lo que equivale a una reforma constitucional) de un cambio en la Constitución (equiparable a una nueva Constitución)? Estas preguntas tienen cierta relevancia política en la discusión actual, porque si lo que ha ocurrido durante los últimos 25 años han sido sólo modificaciones de leyes constitucionales, entonces no importa cuántas veces se haya hecho eso: la Constitución seguirá siendo la misma.

Una manera de avanzar en esta cuestión es mirar lo que para el abogado es importante no con los ojos del derecho, sino desde la perspectiva de la política ${ }^{9}$. Para el abogado, como lo hemos visto, lo decisivo para poder hablar de Constitución es la dificultad de reforma. Ya hemos citado la observación de Ferrajoli conforme a la que las constituciones son rígidas "por definición". Y, como hemos observado, esto lleva al pensamiento jurídico a la conclusión, evidentemente equivocada, de que una Constitución es un texto, y en ese sentido la observación de Ferrajoli es incorrecta. Pero a pesar de eso hay algo que decir acerca de los procedimientos dificultados de reforma. Aunque ellos no definen la Constitución, es verdad que están vinculados a ella, porque lo que es identificado como Constitución es siempre (salvo en casos muy excepcionales) difícil de modificar. Por consiguiente, alguna relación interesante ha de haber entre Constitución y dificultad de reforma.

9. Esto es lo que en Atria: La Constitución Tramposa, pp. 25-29 es tematizado como "hablar al revés". 


\section{SOBRE LA DIFICULTAD DE REFORMA Y SU SENTIDO}

Y, por cierto, hay una relación entre la Constitución y los obstáculos para su reforma. Pero para entenderla deberemos mirarla atendiendo a su sentido político, no a sus efectos jurídicos. Es decir, debemos atender al sentido de la dificultad de reforma. Porque cuando se trata de la Constitución, el sentido de dificultar la reforma es que no sea reformada, mientras que en el resto del texto constitucional el sentido de dificultar su reforma es sólo dar veto a una minoría. Llamaremos a este criterio "el método de la paráfrasis" por razones a ser explicadas a continuación.

\section{Un criterio de distinción: el método de la paráfrasis}

Considérense las siguientes partes del texto constitucional:

"Chile es una república democrática" (art. $4^{\circ}$ ).

"La soberanía reconoce como limitación los derechos fundamentales que emanan de la naturaleza humana" (art. $5^{\circ}$ ).

"Los templos y sus dependencias, destinados exclusivamente al servicio de un culto, estarán exentos de toda clase de contribuciones" (art. $19 \mathrm{~N}^{\circ} 6$ inc. final). "Los fiscales regionales deberán tener a lo menos cinco años de título de abogado" (art. 86, inc. $3^{\circ}$ ).

El método de la paráfrasis consiste en describir estas cláusulas relativizándolas, es decir, añadiéndoles sus condiciones de reforma. La paráfrasis será "correcta" cuando el sentido del enunciado parafraseado (la disposición constitucional no relativizada) sea correctamente capturado por la paráfrasis (el enunciado relativizado):

"Chile es una república democrática, salvo que $2 / 3$ de los senadores y diputados en ejercicio decidan lo contrario" (art. $4^{\circ}$, art. 127 inc. $2^{\circ}$ ).

"La soberanía reconoce como limitación los derechos fundamentales que emanan de la naturaleza humana, a menos que $2 / 3$ de los senadores y diputados en ejercicio decidan lo contrario" (art. $5^{\circ}$, art. 127 inc. $2^{\circ}$ ).

"Los templos y sus dependencias, destinados exclusivamente al servicio de un culto, estarán exentos de toda clase de contribuciones, salvo que $2 / 3$ de los senadores y diputados en ejercicio decidan lo contrario" (art. $19 \mathrm{~N}^{\circ} 6$ inc. final). 
"Los fiscales regionales deberán tener a lo menos cinco años de título de abogado, salvo que $3 / 5$ de los senadores y diputados en ejercicio decidan lo contrario" (art. 86, inc. $3^{\circ}$, art. 127 . inc. $2^{\circ}$ ).

Supongo que el lector estará de acuerdo conmigo en que la paráfrasis es correcta en el caso del art. $19 \mathrm{~N}^{\circ} 6$ y del art. 86, pero no en el caso del artículo $4^{\circ}$ ni del artículo $5^{\circ}$. Esta diferenciación requiere de una explicación, porque en términos estrictamente jurídicos la paráfrasis es correcta en todos los casos. Pero que lo sea en términos estrictamente jurídicos no quiere decir que lo sea en el sentido político que ahora nos importa, sino que una perspectiva estrictamente jurídica ignora algo que es importante. Lo que es relevante es que el sentido de la dificultad de reforma es distinto en el caso de la Constitución y de las leyes constitucionales. En el caso de la Constitución, su reforma está dificultada para que no sea reformada; en el caso de las leyes constitucionales, su reforma está dificultada sólo para dar veto a la minoría. En el primer caso, los mecanismos de reforma protegen la Constitución; en el segundo, protegen los intereses de alguna minoría.

Como normalmente toda la discusión usa el concepto de constitución del abogado sin estar consciente de ello, esta diferencia se pasa por alto y se asume que la Constitución es "un pacto" y que el sentido de la reforma dificultada es sólo dar seguridades a la minoría por la vía de proveerles de un veto. Pero esto es un error, como lo muestra el hecho de que la paráfrasis falla en los dos primeros casos. Dar a la minoría veto y permitirle así imponer sus condiciones no es el sentido de la reforma dificultada de la Constitución, es el efecto que esas reglas tienen. Ambas cosas son evidentemente distintas. Por ejemplo, el efecto que tienen las reglas sobre la validez de un testamento es que si el testador cambió de opinión respecto de la repartición de sus bienes, pero no alcanzó a plasmar esa nueva voluntad en un nuevo testamento, los bienes se distribuirán conforme a la penúltima voluntad del causante. Pero el sentido de la institución testamentaria es hacer probable la identificación correcta de la última voluntad del causante.

Lo que nos interesa ahora no son los efectos, sino el sentido, porque queremos entender, no predecir. Y lo que nos dice el test de la paráfrasis es que dicho sentido es distinto en el caso de la Constitución y de las leyes constitucionales: en el caso de la primera es asegurar, en la medida en que eso puede ser asegurado, que la Constitución no va a cambiar; en el caso de las segundas es dar veto a la minoría ${ }^{10}$.

10. Por supuesto, esto plantea la pregunta por el sentido de las leyes constitucionales. En Atria: La Constitución Tramposa, pp. 41-44 son explicadas como "abuso de la forma constitucional", precisamente porque el sentido de la dificultad de reforma en el caso de la Constitución no 
A lo anterior podría objetarse que no es correcto decir que, tratándose de la Constitución, el sentido de la dificultad de reforma es asegurar que ésta no va a ser cambiada. Si fuera así, lo que habría que hacer, por cierto, es decretar que esas cláusulas son "pétreas", en el sentido de que se prohíbe su reforma. Así lo hace, por ejemplo, la Ley Fundamental alemana de 1949, conforme a la cual

No está permitida ninguna modificación de la presente Ley Fundamental que afecte la organización de la Federación en Länder, o el principio de la participación de los Länder en la legislación, o los principios enunciados en los artículos 1 y 20 (art. 79.3)11.

El argumento sería: si el sentido de la reforma dificultada fuera impedir la modificación de la Constitución, entonces toda Constitución sería pétrea. Pero las cláusulas pétreas son excepcionales, y casi todas las constituciones tienen cláusulas que permiten la reforma de cualquier parte de su texto. ¿Cómo podría decirse que el sentido de estas reglas que permiten la reforma es que la Constitución no sea reformada?

Esta objeción asume que si el sentido de los mecanismos dificultados de reforma es impedir que ésta ocurra, lo que sería realmente consecuente sería la prohibición de la reforma, el carácter pétreo de la Constitución. Esto es un error que consiste en entender que los sentidos jurídicos y políticos son unívocos. Si esto fuera así, habría que entender que la cláusula de irreformabilidad de la Ley Fundamental es una manera de asegurar la libertad democrática, asegurarla por la vía de prohibir sus modificaciones futuras. Pero esto no es así. Es precisamente al contrario. Böckenförde lo explica correctamente:

es dar veto a la minoría. Pero nosotros hemos naturalizado la neutralización constitucional y por eso el lenguaje neutralizado y tramposo de la Constitución de 1980 se nos presenta como si fuera un lenguaje aplicable a todas las constituciones, y por eso nos dicen que todas las constituciones neutralizan, que las constituciones son pactos y por consiguiente el sentido de su dificultad de reforma es dar veto a la minoría. En esta explicación el veto no es un abuso, sino lo que se busca; no es un efecto, sino parte del sentido de la dificultad de reforma. Esta comprensión de la Constitución es incompatible con la tradición democrática en el sentido obvio de que no puede entender a la Constitución como constituyendo poder democrático, sino como limitándolo.

11. El art. $1^{\circ}$ de la Ley Fundamental contiene el principio de dignidad humana; el art. 20, por su parte, el principio democrático y el derecho de resistencia. 
Las cláusulas de intangibilidad del artículo $79.3 \mathrm{LF}$ no son un reflejo de la libertad democrática, sino más bien una limitación sustantiva de ésta, en tanto se sitúan más allá de las condiciones constitutivas de la formación democrática de la voluntad. Tienen como objetivo impedir una 'revolución legal', esto es, una transformación que destruya por medios legales los fundamentos del orden político y jurídico, y por eso pretenden vincular jurídicamente también a las generaciones futuras. Son en realidad un signo de que una comunidad política -en este caso la del pueblo alemán después de 1918 y, especialmente, después de la perversión del ordenamiento estatal en la época de 1933-1945- ha perdido la confianza en sí misma ${ }^{12}$.

"Una comunidad que ha perdido la confianza en sí misma". Confianza en qué, podríamos nosotros preguntar. Confianza en que a través de la discusión y decisión democrática el principio democrático podrá ser defendido. Es decir, confianza en que el principio democrático tiene fundamentos políticos suficientemente fuertes y no está expuesto en todo momento a ser derrotado. Confianza en que el pueblo puede ser quien decida qué es lo que en las circunstancias exige el principio democrático.

Por supuesto, quienes defienden la Constitución de 1980 y su abuso de la forma constitucional insisten en este punto, como si en la experiencia política chilena la negación del principio democrático y la violación de derechos hubiera sido consecuencia, como en Alemania, de un pueblo que se vuelve contra la democracia. Por cierto, nuestra historia es precisamente la contraria: los derechos y la democracia se acabaron cuando así decidió hacerlo el "mismo sector social que hoy estará en sus casas, esperando con mano ajena reconquistar el poder para seguir defendiendo sus granjerías y sus privilegios" ${ }^{13}$. A diferencia de la alemana, la historia de Chile no justifica que los chilenos tengamos falta de confianza política en nosotros mismos.

$\mathrm{Y}$ aquí puede ser importante volver sobre la distinción entre el sentido de una regla y sus efectos. Porque el sentido de una regla que prohíbe reformar la cláusula de la dignidad humana, por ejemplo, es que no se negará la dignidad humana. Pero el efecto es que el texto que la expresa no puede ser tocado. Y esto evita que a través de la reforma el sentido políticamente relevante de un principio constitucional vaya surgiendo.

Tenemos un buen ejemplo para explicar esto último. Porque el equivalente en el texto constitucional chileno actual de una de las cláusulas pétreas de la Ley

12. Böckenförde: "La democracia como principio constitucional", en Estudios sobre el Estado de Derecho y la Democracia (Madrid: Trotta, 2000), pp. 47-131, aquí p. 81.

13. Allende, Discurso final (La Moneda, 11 de septiembre de 1973). 
Fundamental alemana, el inciso $1^{\circ}$ del artículo $1^{\circ}$ (principio de dignidad humana), ha sido, de hecho, modificado. Este es un buen ejemplo para comentar el sentido de una reforma constitucional, porque es claro que se trata de una disposición que conforme al test de la paráfrasis no es una ley constitucional, sino parte de la Constitución.

En efecto, el artículo $1^{\circ}$, inciso $1^{\circ}$, disponía que (cito el texto anterior a la ley 19.611):

Los hombres nacen libres e iguales en dignidad y derechos (art. $1^{\circ}$ inc. $\left.1^{\circ}\right)$.

Pero no es correcto decir sin más que:

Los hombres nacen libres e iguales en dignidad y derechos, salvo que $2 / 3$ de los senadores y diputados ejercicio decidan lo contrario" (art. $1^{\circ}$ inc. $1^{\circ}$, art. 127 inc. $2^{\circ}$ ).

Pero aunque el artículo $1^{\circ}$, inciso $1^{\circ}$, es parte de la Constitución, su texto fue modificado por la ley 19.611, en los siguientes términos:

Artículo único: Introdúcense las siguientes modificaciones en la Constitución Política de la República de Chile:

1) Sustitúyese en el inciso primero del artículo $1^{\circ}$, la expresión 'Los hombres' por 'Las personas'...”.

A mi juicio, explicar el sentido político de la ley 19.611 implica afirmar, primero, que hay algo importante en que el texto constitucional ya no use el término "hombres" para referirse a la humanidad completa. El punto no es semántico o gramatical, como insisten quienes pedantemente nos recuerdan cada cierto tiempo que en castellano el masculino es genérico. El punto es político y pretende hacer visible precisamente lo que significa el hecho de que el masculino sea genérico. En este sentido, es importante que la Constitución ya no use "hombres".

Pero, adicionalmente, es necesario decir que la ley 19.611 no cambió la Constitución. Es decir, que la reforma sólo hizo explícito lo que estaba implícito en la formulación anterior. El sentido de la nueva formulación no era negar la anterior y afirmar una nueva, distinta, sino hacer el mismo significado que ya estaba en la formulación anterior, más transparente, más explícito. Dicho de otro modo, el texto fue modificado, pero no la Constitución. Lo que asegura ${ }^{14}$ que la Constitución no

14. "Asegura" en sentido institucional, en que eso quiere decir: "hace probable", no "hace necesario". Al respecto, véase Atria: La Forma del Derecho (Madrid: Marcial Pons, 2016), pp. 133158. 
será modificada, pero que el texto será modificado en la medida en que eso sea necesario, es el mecanismo dificultado de reforma. Y por eso el argumento anterior (que cuando se trata de la Constitución el sentido de la dificultad de reforma es que no será modificada) no implica, ni siquiera en principio, que las cláusulas constitucionales han de ser jurídicamente pétreas.

Por consiguiente, podemos decir que el sentido de los mecanismos de reforma constitucional es hacer posible la reforma del texto constitucional, pero sin modificación de la Constitución.

Nótese que para explicar lo anterior hemos recurrido no a las reformas que en materias políticas son más controvertidas (la de 2005, por ejemplo), sino a una que no dio mucho que hablar, que fue relativamente pacífica. Y lo fue precisamente porque todos sabían que se estaba reformando el texto, no cambiando la Constitución; que se trataba de encontrar una mejor formulación para el principio de dignidad humana, no de negar ese principio y afirmar uno distinto. Lo que hemos visto en operación en materia de reformas constitucionales en los últimos 25 años es lo mismo, aunque aquí "la Constitución" es algo mucho menos digno que una declaración genérica de reconocimiento de la dignidad humana; es la neutralización que define a la Constitución de $1980^{15}$. El efecto, sin embargo, es el mismo: el texto constitucional (las leyes constitucionales) ha sido modificado una y otra vez, pero la Constitución no ha sido tocada.

\section{Un caso de comprensión precisamente invertida}

Es importante destacar que la conclusión anterior, que señala que la Constitución no puede ser modificada mediante los mecanismos de reforma constitucional y que esos mecanismos sólo sirven para reformar las leyes constitucionales, debe ser distinguida de la tesis que afirma que, jurídicamente hablando, el "poder constituyente derivado" carece de facultades para modificar el texto de algunas disposiciones.

Esta segunda tesis aparece de vez en cuando en la discusión en la forma de profesores de Derecho que simplemente decretan que algunas cosas "no se pueden hacer". Y nos dicen que no se pueden hacer no porque estén prohibidas por una regla, sino por razones conceptuales, porque dado lo que las palabras significan, lo constituido no puede estar por sobre lo constituyente, etc. La tesis debe ser discutida, porque su conclusión (la Constitución no puede ser reformada) es acertada, aunque

15. Véase Atria: La Constitución Tramposa, pp. 31-84. 
su explicación, y por consiguiente las consecuencias que se siguen de esa tesis, son completamente distintas de las que a mi juicio son correctas.

El Profesor Mario Verdugo ha argumentado de este modo. Él cree que "desde una perspectiva estrictamente jurídica nos parece inviable que el Poder Constituyente derivado tenga facultades para avalar el reemplazo del ordenamiento superior cuya vigencia debe precisamente cautelar" ${ }^{\prime \prime}$. A mi juicio, el Profesor Verdugo aquí está precisamente incurriendo en el error de entender jurídicamente lo que sólo tiene sentido políticamente.

Uno podría comenzar preguntándose: ¿qué quiere decir esto de que los poderes constituidos tienen el deber preciso de cautelar la Constitución? ¿En qué sentido un parlamentario, por ejemplo, que ha sido elegido con un discurso que descansa en la necesidad de cambiar la Constitución por tramposa, tiene el "deber preciso" de cautelarla? Desde luego, no puede ser un deber moral. ¿Podrá ser un deber jurídico? Entonces tendríamos que decir que al actuar con la finalidad de producir un cambio constitucional, estaría actuando ilícitamente. Pero esto no tiene sentido. Nótese que no tiene sentido decir que por actuar con esa finalidad está infringiendo su deber. Si al hacerlo actúa contraviniendo la ley, por ejemplo, no hay problema en decir que su acción es ilícita, pero eso no muestra la existencia de un "deber preciso de cautelar la Constitución”, porque en ese caso su acción será ilegal no por haber violado ese (imaginario) deber, sino por la mucho más pedestre razón de que ha violado la ley.

El Profesor explica que se trata de una cuestión de las facultades que la Constitución confiere al "poder constituyente derivado", al que la Constitución no permite la modificación total.

Pero podemos formular la misma pregunta: ¿qué fundamento hay para concluir esto, "desde una perspectiva estrictamente jurídica"? La verdad es que el argumento del Profesor Verdugo es una notoria petición de principios. Él nos recuerda lo que disponen los artículos $6^{\circ}$ y $7^{\circ}$. El primero dispone que la Constitución obliga "tanto a los titulares o integrantes de [los órganos del Estado] como a toda persona, institución o grupo", mientras el segundo dispone que "Ninguna magistratura, ninguna persona ni grupo de personas pueden atribuirse, ni aun a pretexto de circunstancias extraordinarias, otra autoridad o derechos que los que expresamente se les hayan conferido en virtud de la Constitución o las leyes".

Después de citar los textos anteriores, el profesor añade: "Como es obvio, ninguna disposición del Código Fundamental otorga competencia o facultad a alguno de sus órganos para promover la derogación total de su texto". Y, claro, si el poder constituyente derivado no tiene competencia ni facultad para modificar

16. Verdugo: "Nueva Constitución (¿Cómo se logra?)", en DiarioConstitucional.cl (18 de julio 2015) 
enteramente la Constitución, entonces conforme a los artículos $6^{\circ}$ y $7^{\circ}$ no puede modificar el texto enteramente. Pero la cuestión evidentemente es: ¿por qué el Profesor Verdugo cree que es "obvio" que el poder constituyente "derivado" no puede promover una reforma total? La regla habilitante, después de todo, permite modificar cualquier disposición sin limitación alguna más que la procedimental:

Artículo 127. Los proyectos de reforma de la Constitución podrán ser iniciados por mensaje del Presidente de la República o por moción de cualquiera de los miembros del Congreso Nacional, con las limitaciones señaladas en el inciso primero del artículo 65.

El proyecto de reforma necesitará para ser aprobado en cada Cámara el voto conforme de las tres quintas partes de los diputados y senadores en ejercicio. Si la reforma recayere sobre los capítulos I, III, VIII, XI, XII o XV, necesitará, en cada Cámara, la aprobación de las dos terceras partes de los diputados y senadores en ejercicio.

Por alguna razón que no explica, el Profesor Verdugo no ve en el artículo 127 una habilitación amplia para reformar el texto constitucional, cualquier parte de él y cualquier cantidad de disposiciones del mismo. Y entonces concluye que el "poder constituyente derivado" no tiene competencia para la modificación total, por lo que conforme a los artículos $6^{\circ}$ y $7^{\circ}$ se trataría de una acción nula, etc. ${ }^{17}$

Todo lo anterior, sin embargo, es sólo "desde una perspectiva estrictamente jurídica". Porque inmediatamente después de haber llegado a esa conclusión, el Profesor agrega:

17. Yo nunca he entendido qué agregan los artículos $6^{\circ}$ y $7^{\circ}$ en una discusión sobre la constitucionalidad de algo (en este caso, la constitucionalidad de la reforma total). Ellos son citados prácticamente siempre por los constitucionalistas, pero su invocación casi siempre envuelve una evidente petición de principios. Porque en el sentido en el que son habitualmente utilizados, ellos significan: la acción ilegal o inconstitucional de un órgano del Estado es ilícita. Es decir, se trata de una regla que se aplica cuando una acción estatal es ilegal o inconstitucional. Antes de calificar una acción como ilegal o inconstitucional, la referencia a los artículos $6^{\circ} \mathrm{y}$ $7^{\circ}$ es impertinente, y después de esa calificación es redundante. En el caso que nos ocupa, el argumento del Profesor Verdugo es (1) Los arts. $6^{\circ}$ y $7^{\circ}$ : los órganos del Estado están sometidos a la Constitución y sólo tienen las facultades que ésta y las leyes le confieren; (2) El poder constituyente "derivado" no tiene facultades para reformar completamente la Constitución. De ambas premisas, el Profesor Verdugo concluye que la reforma completa a la Constitución por el poder constituyente "derivado", sería ilícita. Pero eso sólo reitera la segunda premisa. La referencia a los arts. $6^{\circ}$ y $7^{\circ}$ no agrega nada al argumento. Esto queda demostrado por el hecho de que toda la discusión es en torno a si las facultades del poder constituyente "derivado" están limitadas, como le parece obvio al profesor. 
Hasta aquí la opinión producto de la formación o deformación del profesor de Derecho Constitucional.

Otra es la experiencia del profesor de Derecho Político: "Los problemas constitucionales no son primariamente, problemas de derecho, sino de poder. En esencia, la Constitución es la suma de los factores reales de poder que rigen en un país ${ }^{18 .}$

Yo supongo que lo que esto quiere decir es que a pesar de que el poder constituyente derivado no está habilitado para dictar una reforma completa a la Constitución, lo que es decisivo no es qué tipo de habilitación ostente, sino la cuestión política de si tiene o no poder para hacerlo. Y que si tiene ese poder y lo hace, entonces habrá que aceptar que hay una Constitución nueva surgida de un ejercicio del poder constituyente "derivado".

Si esta interpretación del Profesor Verdugo y la manera en que se relaciona la cuestión jurídica de las facultades del poder constituyente derivado con la cuestión política del poder, es correcta, entonces nos encontraremos con que el Profesor entiende todo exacta y precisamente al revés.

Primero, lo que es claro: no hay en el artículo 127 referencia alguna ni al número de disposiciones que pueden ser reformadas ni a la intensidad de las reformas que pueden ser dictadas. Una perspectiva "estrictamente jurídica" es una perspectiva que se limita a observar las cosas desde el punto de vista del derecho vigente, y el derecho vigente no contiene esos límites. Por consiguiente, jurídicamente hablando, el poder constituyente derivado está habilitado para cambiar cualquier parte del texto constitucional, incluso todo el texto. A mi juicio, afirmar lo contrario es, por las razones ya explicadas, totalmente gratuito y arbitrario. Es inventar una cláusula pétrea donde no hay ninguna cláusula pétrea.

Es decir, cualquier disposición de la Constitución, incluso sus artículos más fundamentales, como el inciso $1^{\circ}$ del artículo $1^{\circ}$, puede ser reformada a voluntad del legislador constitucional sin que haya objeción jurídica alguna que oponer al respecto. El Tribunal Constitucional no podría, en caso alguno, declarar la inconstitucionalidad de una ley de reforma constitucional que ha satisfecho las condiciones formales del artículo 127, ya transcritas.

Pero como ya está explicado, esto no quiere decir que la Constitución puede ser reformada. Porque es verdad que no puede ser modificada, es decir, su contenido cambiado mediante actos ordinarios de reforma constitucional. Pero eso no es

18. Verdugo: "Nueva Constitución (¿Cómo se logra?)" (la cita final es a Lasalle: ¿Qué es una constitución? (Buenos Aires: Panamericana, 1994; ed.orig. 1862). 
porque haya una regla jurídica que lo prohíba o porque los individuos que ocupan los cargos públicos tengan un deber jurídico o moral de "cautelar" la Constitución. Es porque el sentido de los procedimientos de reforma es hacer (suficientemente) improbable un cambio de la Constitución. Entonces, es precisamente desde una óptica política, no "estrictamente jurídica", que el carácter inmodificable de la Constitución aparece.

\section{El contenido de la forma: un cubo de Necker constitucional}

Una de las peculiaridades más notorias de una posición como la del Profesor Verdugo es la completa independencia de lo que él llama "una perspectiva estrictamente jurídica" y la perspectiva "del poder", de lo que él cree que puede decir como profesor de Derecho Constitucional, por una parte, y como profesor de Derecho Político, por la otra. El que desde la primera óptica la nueva Constitución sea imposible mediante el ejercicio de poderes institucionales no significa que esto sea verdad ${ }^{19}$. Uno se pregunta entonces cuál es el sentido del derecho, si no es precisamente hacer imposible o al menos improbable lo que es contra derecho (dicho de otro modo, qué le queda de "derecho" al profesor de Derecho Político).

Es decir, una reflexión que enfatiza que es jurídicamente imposible dar una nueva Constitución a través de mecanismos institucionales no puede simplemente limitarse a terminar diciendo que lo que es jurídicamente imposible lo puede hacer, sin más, la política.

Por cierto, al decir esto no estoy asumiendo la posición ingenua del que cree que lo que el derecho declara ilícito será, por ello, políticamente imposible. Es verdad que la relación entre política y derecho no es tan simple. Pero no puede ser que el hecho de que no sea tan simple nos lleve a decir que la conclusión jurídica es totalmente irrelevante para los asuntos constitucionales que, después de todo, no serían "problemas de derecho, sino de poder".

De nuevo, aquí parece haber una relación especial que está subteorizada. Una manera de proceder a la que ya hemos recurrido es intentar hablar al revés, observando cómo se ve la política desde el derecho, o el derecho desde la política. Para hacerlo, debemos poner a cada lado la caracterización jurídica de la distinción entre nueva Constitución y reforma constitucional, y la caracterización política de la misma distinción. Jurídicamente, como hemos visto, se trata de reforma constitucional

19. La única consecuencia del argumento, entonces, es hacer aún más difícil la nueva Constitución, al sugerir que tendría sentido, desde una perspectiva "estrictamente jurídica", que el Tribunal Constitucional declarara inconstitucional por razones de fondo una reforma constitucional, cuando a la bancada dominante en esa tercera cámara dicha reforma le parezca equivalente a un reemplazo de la Constitución. 
cuando se hace conforme a los procedimientos de reforma preexistentes, y se trata de nueva Constitución cuando se trata de cualquier otra forma. Políticamente, por su parte, es nueva Constitución cuando cambia la decisión fundamental sobre la forma del poder, y reforma constitucional cuando cambia el texto constitucional sin que cambie esa decisión fundamental, cuando sólo cambian las leyes constitucionales. ¿Qué hemos de decir al respecto? ¿Hay entre estas dos maneras de explicar la diferencia entre nueva Constitución y reforma constitucional alguna relación (como si se tratara del equivalente político-constitucional del cubo de Necker), o cada una está hablando de cosas distintas?

A mi juicio, la situación es la primera: ambas respuestas, la política y la jurídica, están diciendo lo mismo, aunque lo hacen usando lenguajes diferentes. Porque la decisión fundamental sobre la forma del poder (es decir, la Constitución) no es sólo una decisión abstracta o teórica. Es una decisión que se manifiesta en instituciones. Esas instituciones, entonces, contienen la decisión fundamental, y por consiguiente su acción la ratifica y no puede impugnarla. Nótese: la Constitución no es una decisión "teórica", sino una decisión que constituye, que se manifiesta en órganos, formas institucionales, procedimientos. Esos órganos, instituciones y procedimientos existen para realizar la Constitución. No se trata de que tengan un deber jurídicamente exigible de proteger la Constitución, sino que están constituidas para que su operación normal, de hecho, la proteja. Es decir, en lo que ahora nos importa, están constituidos precisamente para que muchas cosas puedan cambiar, pero no el suelo donde se yerguen. Y eso no jurídicamente, no en el sentido de que haya una regla que prohíba la modificación o imponga el deber de no modificar, sino políticamente, en el sentido de que será imposible (o sea, suficientemente improbable) satisfacer las condiciones de reforma constitucional cuando se trate de cambiar la Constitución.

Es la misma conclusión a la que antes habíamos llegado: el sentido de los mecanismos dificultados de reforma es hacer suficientemente improbable el cambio de la Constitución, aunque posible (sólo difícil) el cambio del texto constitucional, las leyes constitucionales. Y nótese que, hasta cierto punto, esto vale incluso cuando formalmente no existen mecanismos dificultados de reforma si la Constitución tiene legitimidad suficiente. En ese caso, el solo hecho de que algo sea visto como cambio de la Constitución es suficiente. En efecto, esto vale incluso

en Estados donde, como ocurre en Inglaterra, por virtud de la pretendida soberanía del Parlamento inglés, pueden acordarse leyes constitucionales en vías del procedimiento legislativo ordinario. Sería incorrecto sostener que Inglaterra 
pudiera transformarse en una República soviética mediante 'simple acuerdo mayoritario del Parlamento' ${ }^{20}$.

Cuando la decisión fundamental es, como en Chile, una de neutralización, esa decisión también se manifiesta en instituciones, que es donde se contiene la decisión neutralizadora. La neutralización no es una decisión de esas instituciones, sino algo acerca de ellas. Por consiguiente, en la medida en que nuevas decisiones se tomen a través de esas formas institucionales, la decisión fundamental en la que dichas instituciones descansan será ratificada, no podrá ser impugnada.

Es importante entender correctamente esta idea de Schmitt. A mi juicio, Schmitt no está diciendo que conforme al derecho inglés el Parlamento de Westminster carece de competencia para dictar una ley conforme a la cual "Inglaterra es una república soviética". De hecho, es un tema pacífico en la reflexión jurídica sobre el poder del Parlamento en Inglaterra que, salvo hacer de un hombre una mujer o viceversa, tiene competencia para decidir cualquier cosa. Esta es la doctrina de Dicey sobre la soberanía del Parlamento que (especialmente en nuestra época, por la Unión Europea, etc.) es discutida, pero es en buena medida (sin duda en la época en que escribía Schmitt) ortodoxa ${ }^{21}$. Mas, por otro lado, tampoco tiene sentido entender que Schmitt está haciendo predicciones sobre el futuro: no está intentando predecir qué es lo que querrá hacer o no una mayoría futura de los miembros elegidos del Parlamento de Westminster. ¿En qué sentido está hablando, entonces? A mi juicio, la mejor explicación es entenderlo políticamente. Schmitt lo dice con precisión: si hubiera una decisión de ese tipo, sería "incorrecto" sostener que se trata de "un simple acuerdo mayoritario del Parlamento", porque lo correcto sería decir que no es un "simple acuerdo", sino un golpe de Estado o una declaración de independencia (dependiendo de si uno está contra él o con él), y el cuerpo que lo tomó no es el Parlamento de Westminster, sino una facción golpista o una asamblea revolucionaria. Lo que esto implica es que la discusión sobre el sentido de la nueva Constitución debe ser una discusión enteramente purgada de formalismos jurídicos. Esto opera en ambos sentidos: como es enteramente purgada, no tiene sentido decir que una nueva Constitución no se puede dar fuera de mecanismos "institucionales", pero tampoco tiene sentido decir que no se puede dar a través de esos mecanismos. Este es el sentido de la afirmación de que el poder constituyente no está atado por las instituciones constituidas: como es pura sustancia (porque es el origen de toda forma), no está vinculado por las formas.

20. Schmitt: Teoría de la Constitución (Madrid: Alianza, 1992; ed.orig. 1928), p. 114.

21. Véase Goldsworthy: Parliamentary Sovereignty (Cambridge: Cambridge University Press, 2010). 
Pero, ¿no habíamos dicho lo contrario? ¿No hemos repetido más arriba, una y otra vez, que una nueva Constitución no puede darse mediante el ejercicio normal de los poderes constituidos? ¿Y ahora resulta que la ausencia de todo formalismo implica que la nueva Constitución puede surgir desde dentro o fuera de esos procedimientos? ¿No hay aquí una evidente contradicción?

La habría si la tesis defendida en este artículo fuera conceptual. Pero no la hay en la medida en que estamos hablando políticamente. Si de lo que se trata es de una nueva Constitución, no tiene sentido mirar a los procedimientos institucionales de reforma, porque esos mecanismos existen para proteger la Constitución existente. Pero si a pesar de esto se usan esos mecanismos, habrá que decir que esa decisión, a pesar de que formalmente se aprobó de un modo determinado, en realidad no fue ejercicio de poderes ordinarios de reforma, sino que una decisión constituyente que se manifestó a través de esas formas. Por cierto, lo que el derecho intenta es impedir que esto último ocurra; pero en su relación con la política el derecho no puede hacer cosas imposibles, sino sólo más o menos improbables. Por eso, la tesis de que no se puede cambiar la Constitución a través de mecanismos institucionales de reforma significa que el derecho hace tan difícil el cambio institucional de la Constitución, que para hacerlo es necesario muchísimo poder político; cuando esa cantidad de poder político está disponible, ya no tiene sentido usar los mecanismos institucionales de reforma. Que dichos mecanismos sean utilizados normalmente significa que no hay suficiente poder político disponible para un cambio constitucional. El uso de esos mecanismos, forzado por el déficit de poder político, implica que la Constitución no será cambiada.

Como puede verse, el punto es el mismo, ya sea hablando el lenguaje jurídico de competencia, facultades y prohibiciones, o el lenguaje político del poder y su cantidad: cuando se recurre a los mecanismos de reforma constitucional, la Constitución no puede ser cambiada, aunque las leyes constitucionales pueden modificarse. Kelsen y Schmitt están aquí diciendo lo mismo en lenguajes distintos.

\section{PODER CONSTITUYENTE Y PODER CONSTITUIDO}

Para terminar, puede ser útil mostrar cómo las consideraciones anteriores se proyectan sobre el predicamento político constitucional chileno, por referencia a la idea de poder constituyente, como una manera de expandir las consideraciones finales de la sección anterior.

Los constitucionalistas habitualmente distinguen dos formas de lo que ellos llaman "poder constituyente", el "derivado" y el "originario". Esto es consecuencia del hecho de que ellos entienden que una Constitución es un texto y su pregunta es 
quién puede (o sea, "tiene poder para") escribir ese texto. Ellos responden: el texto puede ser escrito o reescrito por quienes han sido autorizados por el texto mismo (poder constituyente derivado) o por quien, pese a no estar autorizado por el texto, tiene poder para hacerlo (poder constituyente originario). Esto es lo que los lleva a decir que "poder constituyente" es un género del que "derivado" y "originario" son sus especies. Cuando el concepto de Constitución formal del abogado es remplazado por el concepto político que hemos explicado más arriba, la cuestión cambia notoriamente.

Porque entonces el poder constituyente es el poder para dar una nueva Constitución, es decir, para decidir sobre la forma y modo de ejercicio del poder. La manera en que esa decisión se expresa, como ya hemos observado, es constituyendo, creando instituciones. Las instituciones creadas son manifestación de la Constitución, de la decisión fundamental sobre la forma del poder. Por eso, esas instituciones protegen la Constitución, no (permítaseme insistir) en virtud de un deber jurídico de cautela, sino porque su constitución, el modo en que están institucionalmente configuradas, tiene el sentido de impedir (es decir, hacer improbable) el cambio de la decisión fundamental sobre la forma del poder.

Entonces, poder constituyente originario y poder constituyente derivado no son dos especies de un mismo género, sino dos cosas totalmente diferentes, pertenecientes a géneros distintos. Porque la distinción relevante es entre poder constituyente y poder constituido, entre el poder de decidir sobre la forma y modo de ejercicio del poder, y el poder que se fundamenta en una decisión sobre la forma y modo de ejercicio del poder y que en consecuencia tiene un punto ciego: no puede impugnar esa decisión.

Los poderes constituidos son de distinto tipo: poderes normativos y poderes de acción, poderes normativos de aplicación y de creación, etc. Todos estos poderes tienen una cosa en común: son configurados por normas jurídicas, y aquí tiene sentido hacer referencia a los artículos $6^{\circ}$ y $7^{\circ}$ : las normas jurídicas, respecto de estos poderes, fijan el modo de legitimación orgánico personal de sus integrantes, sus procedimientos de actuación y su competencia. Ahora nos interesan especialmente los poderes normativos, es decir, los poderes que se ejercen creando normas. Son poderes normativos el poder jurisdiccional, la potestad reglamentaria del Presidente de la República, el Poder Legislativo. También es, en este mismo sentido, un poder normativo el poder de dictar o reformar leyes constitucionales, que podría llamarse poder legislativo-constitucional. Lo que es distinto en todos estos casos es su institucionalización: el órgano que lo detenta, la composición de ese órgano, su competencia, sus modos de ejercicio (procedimientos), etc. Lo que es común a todos ellos es que se trata de poderes institucionalmente conferidos, poderes que los órganos respectivos tienen en virtud de normas jurídicas que se los confieren y que les fijan modos de ejercicio, procedimientos, etc. Como ya hemos insistido, parte 
del sentido de esas normas que especifican la competencia y los procedimientos de ejercicio de los órganos constituidos es defender la Constitución en el sentido ya explicado más arriba.

El poder constituyente, por su parte, no es ni puede ser un poder normativo. O mejor dicho, es y no es un poder normativo. Es un poder normativo en un sentido diverso al anterior, porque crea normas. Pero no es un poder normativo en el sentido en el que lo son los poderes ya mencionados (la potestad legislativa en cualquiera de sus formas, la jurisdiccional, la reglamentaria), porque no es un poder institucionalmente configurado, no es un poder conferido y regulado por normas jurídicas. Es lo que podríamos llamar "poder informe", poder político que no tiene forma.

Poder, en este sentido, es la capacidad de los seres humanos de actuar en concierto $^{22}$. El derecho crea poder porque al crear formas y procedimientos especifica modos de acción concertada, que entonces dispensan de la necesidad de un momento especial de coordinación. El derecho especifica quién decide qué y otras "instituciones" se coordinan por referencia al derecho: si una institución actúa dentro de la esfera de sus competencias y mediante el procedimiento respectivo, entonces las demás deben acatar lo decidido por la primera y actuar en concierto de acuerdo a lo que dispone el derecho, etc. Esto es lo que quiere decir eso de que "las instituciones funcionen": que todas las personas deben concertarse en su acción de acuerdo al modo en que las instituciones constituidas especifican que deben hacerlo.

Por supuesto, el hecho de que el derecho pretenda crear instituciones con poder (es decir, instituciones que permitan y maximicen la capacidad humana de actuar en concierto) no quiere decir que sea exitoso en eso. La fortaleza de las instituciones en un lugar o momento determinado depende de cuán exitoso es el derecho en la creación de poder político. Y para apreciar la importancia de este punto es central entender que el poder es susceptible de un análisis que podríamos llamar cuantitativo. En el sentido ya explicado, las instituciones existen para crear poder: como se trata de un poder normativamente configurado, es un poder que se somete a la Constitución, no porque haya una regla que ordena que todos los órganos han de someterse a ella (que puede o no haber), sino en el sentido de que están configurados para actuar en términos de la Constitución (no el texto, sino la decisión sobre la forma del poder). Cuando las instituciones son exitosas, crean mucho poder; cuando no son exitosas, crean poco poder (o nada). Es importante notar que como las instituciones pueden ser más fuertes o más débiles, más o menos exitosas, el poder que ellas crean es

22. Arendt: On Violence (San Diego, CA: Harcourt Brace and Company, 1969), p. 44. 
algo que puede o no existir, y que puede existir en cantidades: puede haber mucho o poco poder, etc.

La deslegitimación de una forma institucional la hace perder poder. A mi juicio, eso es lo que ha estado pasando con la institucionalidad chilena notoriamente desde 2001, el año en que los chilenos perdimos la inocencia constitucional. Pero no es eso lo que me interesa comentar aquí23. El punto ahora es que el poder constituyente, como es un poder informe, es un poder que no es creado por el derecho ni por las instituciones. Esto tiene varias consecuencias importantes:

(a) Es un poder que se ejerce impugnando la decisión constituyente anterior y dando al poder institucional (constituido) una nueva forma y modo de ejercicio. El poder constituyente puede hacer esto precisamente porque no es un poder institucional, y por eso no está sujeto a las relativizaciones, caracterizaciones, procedimientos y modos de ejercicio propios de los poderes institucionales.

(b) Como se ejerce ignorando la decisión constitucional anterior, el poder puede ser descrito como "constituyente" cuando se trata de un poder no institucionalmente informado que ha alcanzado una magnitud suficiente para impugnar la decisión constitucional vigente y tomar una nueva.

(c) Pero precisamente porque se trata de un poder no institucionalmente informado y que tiene una magnitud especialmente alta, es un poder altamente improbable: en sociedades masivas, complejas y diferenciadas, es altamente improbable que los seres humanos alcancen esa capacidad de actuar en concierto sin la mediación de las instituciones jurídicamente configuradas.

Se sigue de lo anterior que un proceso constituyente es un proceso de acumulación de poder político no institucionalmente mediado. Si el proceso ha de ser exitoso, el poder aumentará hasta alcanzar la magnitud necesaria para ser constituyente, para poder prescindir de las limitaciones inherentes a los poderes constituidos y tomar una decisión sobre la forma y modo de ejercicio del poder. Aquí el argumento presente sobre el poder constituyente se vincula al argumento anterior respecto a la posibilidad de usar un poder constituido para expresar una nueva Constitución. Si el poder no institucionalmente mediado ha alcanzado la magnitud suficiente para ser poder constituyente, ya no tiene sentido usar las formas institucionales anteriores. En esa situación, la solución será utilizar una forma nueva.

¿Cuándo sí tiene sentido usar las formas institucionales anteriores? Nótese que la pregunta es política, no jurídica: ¿por qué un poder habría de utilizar formas constituidas? La respuesta es relativamente clara: en cualquiera de dos circunstancias: (a) cuando lo que se busca no es cambiar la Constitución o (b)

23. Véase Atria: Veinte Años Después, Neoliberalismo con Rostro bumano (Santiago: Catalonia, 2013)3-5. 
cuando, pese a que se pretende cambiar la Constitución, no se ha acumulado poder suficiente para impugnarla (es decir, cuando hay poder, pero no suficiente para ser constituyente). En ambos casos, el recurso al poder constituido implica que la Constitución no será impugnada. Y así llegaremos a una conclusión que parecerá una conclusión "conceptual", que se sigue del significado de las palabras, pero que es completamente política: el poder constituyente no puede expresarse a través de los poderes constituidos; cuando se expresa a través de los poderes constituidos no es poder constituyente. Esta es una conclusión política, no conceptual, porque el significado político del recurso a los poderes constituidos es precisamente que no se trata de un poder constituyente... pero no se trata de un poder constituyente porque no ha habido suficiente poder no institucionalmente mediado acumulado.

Por cierto, el recurso al poder constituido puede tener el sentido político de ser el modo a través del cual se ejercerá lo que pretendió ser un poder constituyente, y entonces será la marca de su fracaso: no habiendo acumulado suficiente poder para impugnar la Constitución y reemplazarla, deberá contentarse con obtener las modificaciones a las leyes constitucionales que esos procedimientos hagan probable. Esta es exactamente la situación de la reforma constitucional de 2005 y la constante excusa del Presidente Lagos que, enfrentado al hecho de que lo que pretendió ser una nueva Constitución no lo fue, reclama que se hizo lo que fue posible dado el poder que había en ese momento.

O puede tener un sentido diverso: puede ser entendido como parte del proceso de acumulación de poder que haga posible la emergencia de un poder constituyente. A mi juicio, ésta es la pretensión del proceso constituyente en curso: que la discusión ciudadana que ocurra en los Encuentros Locales Autoconvocados primero, y luego en los Cabildos Provinciales y Regionales será un momento de creación de poder y contribuirá a que haya suficiente poder detrás de la demanda por una nueva Constitución como para que cuando llegue el momento institucional, oponerse a la nueva Constitución usando los vetos de la Constitución tramposa resulte ser una estrategia demasiado costosa políticamente. No estoy ahora manifestando una opinión sobre si así entendido el proceso tiene una dimensión constituyente adicional al wishful thinking (yo creo que la tiene), porque sólo estoy intentando ilustrar el sentido en el que recurrir a los poderes constituidos puede ser una forma de contribuir a la formación de poder constituyente ${ }^{24}$.

24. Como en todas las cosas políticas, las cuestiones deben ser analizadas con cuidado. Cuando el proceso constituyente fue anunciado, había dos posibilidades de proceder que estaban, en principio, abiertas: una era la que se eligió, la de recurrir a una reforma del capítulo XV del texto constitucional que conforme a lo dispuesto en el art. 127 requiere del voto de $2 / 3$ de los senadores y diputados en ejercicio; la otra era modificar (por $3 / 5$ de los mismos votos) el art. 
15 y permitir de ese modo la realización de un plebiscito constitucional (lo que evidentemente sería o al menos podría ser una oportunidad extraordinaria para aumentar el poder político detrás de la demanda de nueva Constitución, hasta que alcanzara la magnitud necesaria para ser poder constituyente). En esas condiciones, el anuncio presidencial de que se buscaría una reforma que contara con el voto de $2 / 3$ de los senadores y diputados en ejercicio fue indudablemente un triunfo de quienes no quieren una nueva Constitución. ¿Qué explica ese triunfo? La respuesta es clara: la escasez de poder constituyente. Por consiguiente hay quienes interpretan el proceso constituyente como una instancia de lo primero indicado en el texto principal: como un reconocimiento de que no hay poder constituyente disponible, y que la cuestión constitucional debe ser cerrada ahora, y que por eso es mejor lograr algunas reformas de leyes constitucionales (nótese que no estoy tratando de exculpar, sino de entender: algunos dirán esto porque defienden la actual versión de la Constitución de 1980, otros por "realismo" político, etc.); otros interpretan el proceso constituyente de la segunda manera: como una oportunidad para desarrollar, durante los Encuentros Locales y los Cabildos (y, agregaría yo, como consecuencia de la inevitable percepción de manipulación que va a seguir a la publicación de las "bases", documento que pretenderá dar cuenta de lo discutido en los encuentros locales, pero que será redactado por un cuerpo binominalizado como el Consejo de Observadores), poder constituyente. 